\title{
Influence of Ross Sea Bottom Water changes on the warming and freshening of the Antarctic Bottom Water in the Australian-Antarctic Basin
}

\author{
K. Shimada ${ }^{1}$, S. Aoki ${ }^{1}$, K. I. Ohshima ${ }^{1}$, and S. R. Rintoul ${ }^{2,3,4,5}$ \\ ${ }^{1}$ Institute of Low Temperature Science, Hokkaido University, Sapporo, Japan \\ ${ }^{2}$ CSIRO Marine and Atmospheric Research, Hobart, Tasmania, Australia \\ ${ }^{3}$ Centre for Australian Weather and Climate Research, Hobart, Tasmania, Australia \\ ${ }^{4}$ Antarctic Climate and Ecosystems Cooperative Research Centre, University of Tasmania, Hobart, Tasmania, Australia \\ ${ }^{5}$ CSIRO Wealth from Oceans National Research Flagship, Hobart, Tasmania, Australia \\ Correspondence to: K. Shimada (k_shimada@lowtem.hokudai.ac.jp)
}

Received: 14 October 2011 - Published in Ocean Sci. Discuss.: 2 November 2011

Revised: 11 May 2012 - Accepted: 22 May 2012 - Published: 9 July 2012

\begin{abstract}
Changes to the properties of Antarctic Bottom Water in the Australian-Antarctic Basin (AA-AABW) between the 1990s and 2000s are documented using data from the WOCE Hydrographic Program (WHP) and repeated hydrographic surveys. Strong cooling and freshening are observed on isopycnal layers denser than $\gamma^{n}=28.30 \mathrm{~kg} \mathrm{~m}^{-3}$. Changes in the average salinity and potential temperature below this isopycnal correspond to a basin-wide warming of $1300 \pm 200 \mathrm{GW}$ and freshening of $24 \pm 3 \mathrm{Gt}$ year $^{-1}$. Recent changes to dense shelf water in the source regions in the Ross Sea and George V Land can explain the freshening of AAAABW but not its extensive warming. An alternative mechanism for this warming is a decrease in the supply of AABW from the Ross Sea (RSBW). Hydrographic profiles between the western Ross Sea and George V Land $\left(171-158^{\circ}\right.$ E) were analyzed with a simple advective-diffusive model to assess the causes of the observed changes. The model suggests that the warming of RSBW observed between the 1970s and 2000 s can be explained by a $21 \pm 23 \%$ reduction in RSBW transport and the enhancement of the vertical diffusion of heat resulting from a $30 \pm 7 \%$ weakening of the abyssal stratification. The documented freshening of Ross Sea dense shelf water leads to a reduction in both salinity and density stratification. Therefore the direct freshening of RSBW at its source also produces an indirect warming of the RSBW. A simple box model suggests that the changes in RSBW properties and volume transport (a decrease of $6.7 \%$ is assumed
\end{abstract}

between the year 1995 and 2005) can explain $51 \pm 6 \%$ of the warming and $84 \pm 10 \%$ of the freshening observed in AAAABW.

\section{Introduction}

The abyssal layer of the world ocean is occupied by Antarctic Bottom Water (AABW), which originates from cold dense shelf water formed by large volumes of sea ice produced in Antarctic coastal polynyas (e.g. Orsi et al., 1999; Jacobs, 2004). AABW production is an integral component of the thermohaline circulation, or overturning circulation, and makes an important contribution to the transport and storage of heat, carbon and other properties that influence climate (Broecker, 1997). Understanding the formation process of $\mathrm{AABW}$, and its sensitivity to change, is therefore needed to improve projection of future climate change (e.g. Jacobs, 2004). The Australian-Antarctic Basin is supplied by AABW from the Ross Sea (termed Ross Sea Bottom Water, RSBW, Orsi et al., 1999) and the Adélie and George V Land (AGVL) region (termed Adélie Land Bottom Water, ALBW, Rintoul, 1998; Williams et al., 2008, 2010). As the focus of this paper is on the AABW of the Australian-Antarctic Basin, hereinafter we use AA-AABW to refer to this mixture of RSBW and ALBW. Both RSBW and ALBW are produced when dense shelf waters, formed by heat loss and the addition 


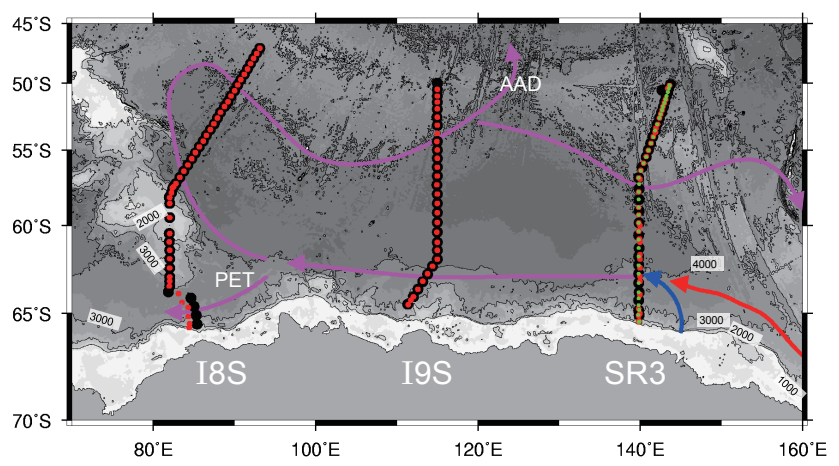

Fig. 1. Locations of the WOCE WHP (black circles) and their repeat (red and green circles) meridional hydrographic sections crossing the Australian-Antarctic Basin with schematic view of spreading path of the AABW. Red circles on SR3 show locations of repeat occupations in the year $2001\left(50-61^{\circ} \mathrm{S}\right), 2002\left(61-66^{\circ} \mathrm{S}\right), 2003$ $\left(61-66^{\circ} \mathrm{S}\right)$ and green circles show those in 2008 , respectively. All the red circles on both I9S and I8S show repeat occupations in the 2000s. Red and blue arrows indicate the RSBW from the Ross Sea and ALBW from the AGVL region respectively and the AA-AABW is indicated by purple arrows.

of brine during sea ice formation in coastal polynyas, overflow down the continental slope and entrain relatively warm Circumpolar Deep Water (CDW) (e.g. Gordon et al., 2004, 2009; Orsi and Wiederwohl, 2009; Williams et al., 2010).

The nature and causes of changes to AA-AABW have been clarified in several recent studies. Whitworth (2002) concluded that two distinct modes of AA-AABW had been produced in the basin, with the cold, fresh mode more prevalent in later observations. Jacobs $(2004,2006)$ concluded that salinity had declined in the region between 140 and $150^{\circ} \mathrm{E}$ south of $65^{\circ} \mathrm{S}$. Aoki et al. (2005) reported a freshening trend at $140^{\circ} \mathrm{E}$ from the early $1970 \mathrm{~s}$. Using hydrographic sections, Rintoul (2007) showed a freshening of AA-AABW across the entire basin. The distribution of CFC-12 indicated that changes are limited to a ventilated layer that had been in contact with the atmosphere within 55 years (Johnson et al., 2008), consistent with the time-scale of changes reported by Aoki et al. (2005) and Rintoul (2007). Changes in the abyssal layer of the world ocean have been traced back to AABW, with the largest changes seen close to the Antarctic continent (Purkey and Johnson, 2010, 2012). In particular, changes in AA-AABW have been identified as the source of changes in the deep North Pacific (e.g. Kawano et al., 2009; Masuda et al., 2010). Identifying the process driving these changes is therefore an important step in understanding changes in the overturning circulation.

Changes in AA-AABW could reflect changes in the properties, volume transport, and mixing ratios of the dense shelf waters. For example, the wide-spread freshening observed in recent decades could reflect an increased supply of meltwater from ice shelves and glacier tongues. The rapid melt of floating ice in the Amundsen-Bellingshausen Seas has been identified as the likely source of the strong freshening trend observed in the shelf waters of the Ross Sea (Jacobs et al., 2002; Zwally et al., 2005; Jacobs and Giulivi, 2010). The changes in temperature of AA-AABW have greater spatial variety and are more difficult to explain. AA-AABW warmed over much of the basin between the years 1936-1993 and 1994-1996 (Whitworth, 2002), but cooled in the region between 140 and $150^{\circ} \mathrm{E}$ from the 1950 to 2001 (Jacobs, 2004, 2006 ) and at $140^{\circ}$ E between the 1970s and 2002 (Aoki et al., 2005), although the magnitude of the trend may be aliased by higher-frequency signals. These overall changes in temperature with space and time suggest that the relative contribution of different source waters may have also played a role in the observed changes of AA-AABW.

Several studies suggest that changes in RSBW and its source waters are likely to have contributed to the changes observed in the Australian-Antarctic Basin. Jacobs (2006) and Rintoul (2007) showed a consistent freshening of RSBW between the Ross Sea outflow and $150^{\circ}$ E. Freshening of shelf waters in the Ross Sea have been attributed in part to the inflow of glacial meltwater from the east (Jacobs et al., 2002; Jacobs and Giulivi, 2010). Changes in sea ice formation are also likely to have played a role. Tamura et al. (2008) inferred a $30 \%$ reduction in the volume of sea ice formed in the Ross Ice Shelf Polynya region from the end of the 1990s to the 2000s. Rivaro et al. (2010) estimated that the export of dense water from the western Ross Sea in 2001 and 2003 are $45 \%$ and $30 \%$ lower than that in 1997, respectively, although these estimates may be subject to aliasing due to higher-frequency variability. Therefore, change in both the properties and volume transport of RSBW may have contributed to observed changes in AA-AABW downstream.

In this study, we describe changes in AA-AABW properties based on CTD profiles of the WOCE Hydrographic Program (WHP) surveys in the 1990s and later repeat surveys in the 2000s. Historical observations are used to track changes in RSBW from the 1970s to the 2000s. A simple advectivediffusive model of downstream evolution of RSBW is then developed to determine the contribution of changes in transport and mixing to its observed changes. Finally, the influences of changes in both RSBW properties and volume transport on AA-AABW are assessed.

\section{Changes to AABW in the Australian-Antarctic Basin}

\subsection{Water mass properties}

AABW in the Australian-Antarctic Basin is supplied by dense shelf water overflows from the Ross Sea and the AGVL region (Fig. 1). AA-AABW flows westward over the continental slope and rise of Wilkes Land towards the Kerguelen Plateau, where it turns north along the plateau (e.g. Fukamachi et al., 2010) until it joins the lower part of the Antarctic Circumpolar Current (ACC) that flows to the east (Orsi et al., 
(a) I8S

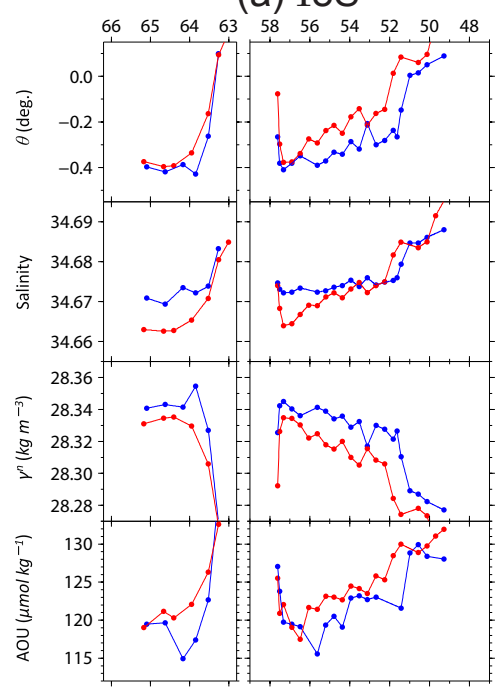

(b) I9S

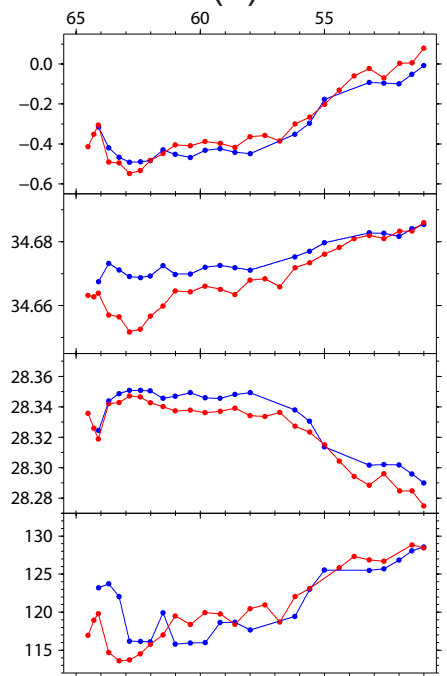

(c) SR3

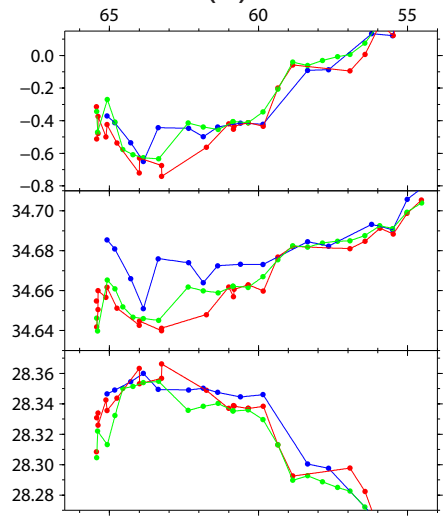

Fig. 2. Meridional variations of the water properties averaged over the $100 \mathrm{~m}$-thick layer at the bottom for (a) I8S, (b) I9S and (c) SR3. Blue circles and lines are from the WHP occupations in the 1990s. Red circles and lines in (c) are from repeat occupations in the year 2001 $\left(50-61^{\circ} \mathrm{S}\right), 2002\left(61-66^{\circ} \mathrm{S}\right), 2003\left(61-66^{\circ} \mathrm{S}\right)$ and green circles and lines in (c) are from those in 2008 . All the red circles and lines in both (a) and (b) are from repeat occupations in the 2000 s.

Table 1. Summary of the WOCE WHP and repeat occupations. The WOCE WHP section designation, years and months and latitudinal range of the WHP and repeat occupations, cruise code names, vessels used for repeat occupations and time intervals.

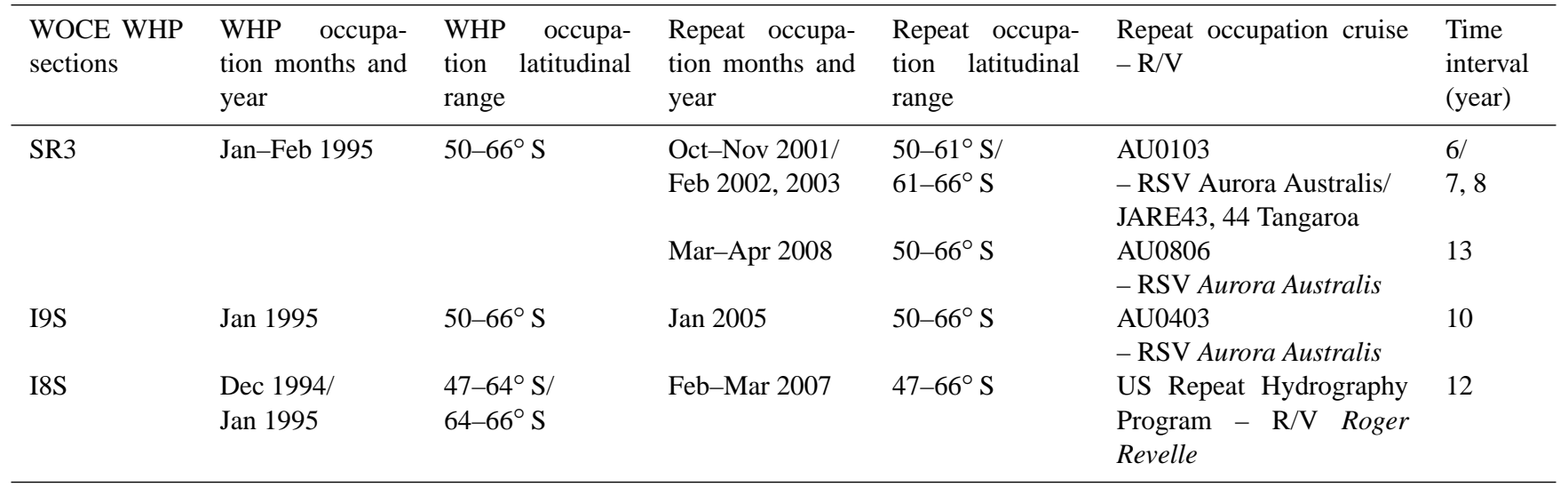

1999). AA-AABW exits the basin through the Princess Elisabeth Trough (PET) and the Australian-Antarctic Discordance (e.g. Rintoul, 2007; Johnson et al., 2008). The WHP sections (I8S, I9S, and SR3 at $82-93^{\circ} \mathrm{E}, 115^{\circ} \mathrm{E}$ and $140^{\circ} \mathrm{E}$, respectively) cross the boundary currents transporting the AAAABW away from the source regions, and each of these sections was conducted in the 1990s and repeated in the 2000s (Table 1). In this section, we describe changes in bottom water properties based on these data.

The SR3 section crosses the AA-AABW path at $140^{\circ} \mathrm{E}$, just downstream of the inflow of ALBW at $\sim 142^{\circ} \mathrm{E}$. Because this line is close to this dense shelf water source, the near-bottom temperature and salinity on the continental slope and rise vary with season and location (e.g. Fukamachi et al.,
2000). To minimize the aliasing due to this seasonal and spatial variability, we focus on near-repeat stations within the same season. For SR3, we supplement the October $2001 \mathrm{sec}-$ tion with stations south of $61^{\circ} \mathrm{S}$ occupied in 2002 and 2003 in the same summer season as the original WHP line (hereafter the combined profiles from 2001-2003 are simply referred to as 2001). The two repeats of $\mathrm{ISS}$ at $115^{\circ} \mathrm{E}$ were also in the same summer season. At I8S section across the western side of the basin at $82-93^{\circ} \mathrm{E}$, the repeated sections were within 2 to 3 months of each other. This section is the furthest from the source regions (over $2500 \mathrm{~km}$ ) and so we expect the seasonal variability to be negligible, as reported for a two-year mooring array close to I8S section by Fukamachi et al. (2010). 

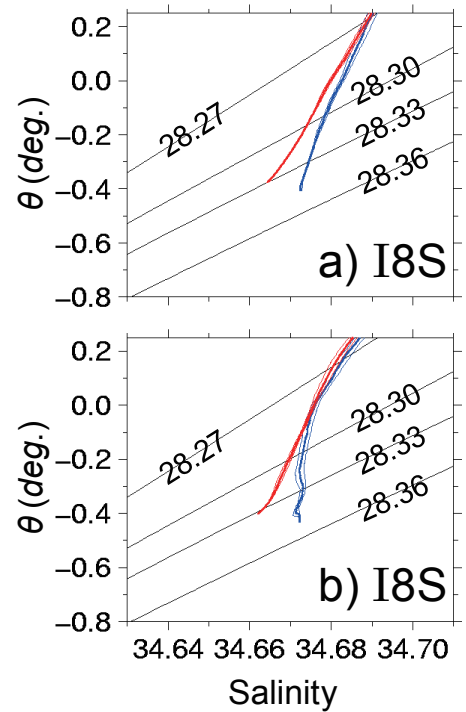
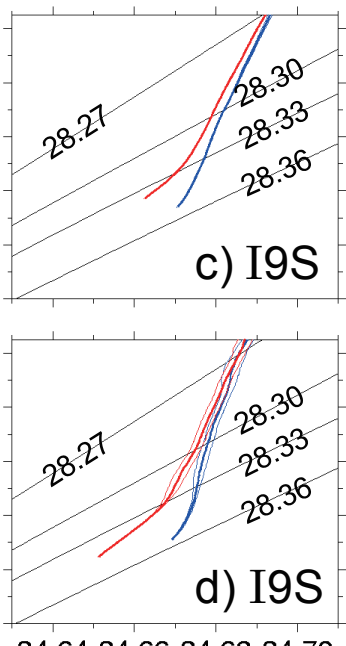

34.6434 .6634 .6834 .70

Salinity

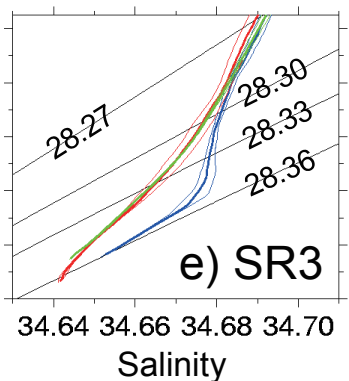

Salinity

Fig. 3. Variations of $\theta-S$ curves for (a) I8S $\left(46-60^{\circ} \mathrm{S}\right.$, the Australian-Antarctic Basin), (b) I8S (60-67 $\mathrm{S}$, the PET), (c) I9S (50-61 $\left.{ }^{\circ} \mathrm{S}\right)$, (d) I9S $\left(61-66^{\circ} \mathrm{S}\right)$ and (e) SR3. Data are averaged on the isopycnal surfaces. Means are shown by thick lines and one standard deviation envelopes are shown by thin lines (following Johnson et al., 2008). Blue lines are from the WHP occupations in the 1990s. Red lines in (e) are from repeat occupations in the year 2001, 2002, 2003 and green lines in (e) are from in the year 2008. All the red lines in other panels are from repeat occupations in the 2000s. Labeled black lines are contour of neutral density $\left(\mathrm{kg} \mathrm{m}^{-3}\right)$.

Decadal changes in the AA-AABW are examined by comparing the meridional variation of potential temperature $\left({ }^{\circ} \mathrm{C}\right)$, salinity, neutral density $\left(\gamma^{n} \mathrm{~kg} \mathrm{~m}^{-3}\right)$ and apparent oxygen utilization (AOU $\mu \mathrm{mol} \mathrm{kg}{ }^{-1}$ ) averaged over a $100 \mathrm{~m}$-thick layer at the bottom (Fig. 2). At SR3, the potential temperature is lower in 2001 and 2008 (by up to $0.1^{\circ} \mathrm{C}$ ) than in the WHP in the 1990 s south of $62^{\circ} \mathrm{S}$. However, the lowest potential temperature $\left(-0.72^{\circ} \mathrm{C}\right)$ was in 2001 and the potential temperature in $2008\left(-0.64^{\circ} \mathrm{C}\right)$ was comparable to that of the WHP in the 1990s. Such a non-monotonic change suggests interannual variability in potential temperature. Cooling $\left(-0.06^{\circ} \mathrm{C}\right)$ was also observed near $63^{\circ} \mathrm{S}$ at I9S. However, warming (up to $0.1{ }^{\circ} \mathrm{C}$ ) is found further downstream along the entire I8S section and north of $61^{\circ} \mathrm{S}$ along I9S. The reversal of sign in the potential temperature changes is also observed in AOU: cooling is associated with a decrease in AOU along I9S south of $62^{\circ} \mathrm{S}$, and warming is associated with an increase in AOU at along I8S and north of $62^{\circ} \mathrm{S}$ on I9S (Fig. 2b). While the changes in salinity do not reverse in sign, the freshening trend is intensified closer to the source region near SR3 and at higher latitudes (up to 0.02). In addition, the bottom layer along SR3 is fresher in 2001 than in 2008 (the minimum salinity south of $62^{\circ} \mathrm{S}$ is lower by 0.01 ). Hence, salinity is also observed to vary interannually. There is no clear change of density near the source of dense water south of $62^{\circ} \mathrm{S}$ on SR3 and near $63^{\circ} \mathrm{S}$ on I9S, because cooling and freshening compensate each other. Further downstream at I8S, and north of $61^{\circ} \mathrm{S}$ on I9S, freshening and warming produces a decrease in density $\left(\sim 0.02 \mathrm{~kg} \mathrm{~m}^{-3}\right)$.
Cooling and freshening on isopycnals reflects warming and/or freshening of water masses where the stratification is such that warmer, more saline waters overly cooler, fresher waters (i.e. density ratio $>1$, Bindoff and McDougall, 1994). Here cooling and freshening is evident on isopycnal surfaces for water denser than $\gamma^{n}=28.30 \mathrm{~kg} \mathrm{~m}^{-3}$ (Fig. 3), indicating basin-wide warming and/or freshening of the AA-AABW. Property differences on isobaric surfaces indicate spatially different patterns between potential temperature and salinity (Figs. 4 and 5). At SR3, the strongest cooling is observed at the sea floor between $63^{\circ} \mathrm{S}$ and $64^{\circ} \mathrm{S}$ (Fig. $4 \mathrm{~d}$, e). At I9S, warming dominated an $\sim 800 \mathrm{~m}$ thick layer below $\gamma^{n}=$ $28.30 \mathrm{~kg} \mathrm{~m}^{-3}$, although weak cooling was detected over the slope south of $62^{\circ} \mathrm{S}$ (Fig. 4c). Freshening dominates everywhere below $\gamma^{n}=28.30 \mathrm{~kg} \mathrm{~m}^{-3}$ with the strongest freshening at the sea floor (Fig. 5c). At I8S, warming (Fig. 4a, b) and moderate freshening (Fig. 5a, b) are observed below $\gamma^{n}=28.30 \mathrm{~kg} \mathrm{~m}^{-3}$.

In summary, following the flow path of the AA-AABW, warming increases downstream and the freshening increases upstream. We estimate the heat and freshwater fluxes needed to explain the observed patterns of change by interpolating the changes observed at each section to the entire basin, using a Gaussian weighting function with an e-folding scale of $300 \mathrm{~km}$ and an influence radius of $1000 \mathrm{~km}$. We find the overall warming of AA-AABW requires an input of $1300 \pm$ $200 \mathrm{GW}$ of heat (or $0.37 \pm 0.05 \mathrm{~W} \mathrm{~m}^{-2}$ ) and $24 \pm 3 \mathrm{Gt} \mathrm{year}^{-1}$ of freshwater (Table 2). 
Table 2. Basin and section averaged trends in property of the AA-AABW. (a) Total volume of layers below $\gamma^{n}=28.30 \mathrm{~kg} \mathrm{~m}^{-3}$ isopycnal, area of the Australian-Antarctic basin, mean potential temperature trend, required heat flux, mean salinity trend, required freshwater input in the Australian-Antarctic Basin. (b) Section averaged thickness of layers below $\gamma^{n}=28.30 \mathrm{~kg} \mathrm{~m}^{-3}$ isopycnals, potential temperature trends, required heat fluxes, salinity trends, required freshwater inputs for respective sections. Error ranges for SR3 were derived from $95 \%$ confidence limit of linear regression coefficient.

(a)

\begin{tabular}{ll}
\hline & Australian-Antarctic Basin \\
\hline Volume $\left(\mathrm{km}^{3}\right)$ & $2.54 \times 10^{6}$ \\
Area $\left(\mathrm{km}^{2}\right)$ & $3.55 \times 10^{6}$ \\
$\Delta \theta\left({ }^{\circ} \mathrm{Cdecade}^{-1}\right)$ & $4.09 \pm 0.53 \times 10^{-2}$ \\
Heat input & $1322 \pm 172(\mathrm{GW}) / 0.37 \pm 0.05\left(\mathrm{~W} \mathrm{~m}^{-2}\right)$ \\
$\Delta S\left(\right.$ decade $\left.^{-1}\right)$ & $-2.67 \pm 0.42 \times 10^{-3}$ \\
Fresh water input & $24.0 \pm 3.2$ \\
$($ Gt year & \\
& \\
\hline
\end{tabular}

\begin{tabular}{|c|c|c|c|c|}
\hline & $\begin{array}{l}\text { I8S } \\
\left(40-60^{\circ} \mathrm{S}\right)\end{array}$ & $\begin{array}{l}\text { I8S } \\
\left(60-67^{\circ} S\right)\end{array}$ & I9S & SR3 \\
\hline Thickness (m) & 761 & 840 & 838 & 695 \\
\hline$\Delta \theta\left({ }^{\circ} \mathrm{C}\right.$ decade $\left.^{-1}\right)$ & $7.65 \times 10^{-2}$ & $4.22 \times 10^{-2}$ & $3.72 \times 10^{-2}$ & $2.14 \pm 2.41 \times 10^{-2}$ \\
\hline Heat flux $\left(\mathrm{W} \mathrm{m}^{-2}\right)$ & 0.75 & 0.46 & 0.40 & $0.19 \pm 0.22$ \\
\hline$\Delta S\left(\right.$ decade $\left.^{-1}\right)$ & $-1.15 \times 10^{-3}$ & $-2.82 \times 10^{-3}$ & $-3.14 \times 10^{-3}$ & $-4.22 \pm 2.24 \times 10^{-3}$ \\
\hline $\begin{array}{l}\text { Fresh water input } \\
\left(\mathrm{mm} \mathrm{m}^{-2} \text { year }^{-1}\right)\end{array}$ & 3.5 & 7.5 & 8.3 & $9.0 \pm 4.6$ \\
\hline
\end{tabular}

\subsection{Potential mechanisms of the observed changes}

Perhaps the most obvious candidate responsible for the observed freshening is a decrease in salinity of the dense shelf waters, as observed in the Ross Sea $\left(-0.03 \mathrm{decade}^{-1}\right.$ since the 1960s, Jacobs and Giulivi, 2010). Freshening by up to -0.01 decade $^{-1}$ is also observed in the George $\mathrm{V}$ Land (G. D. Williams, personal communication, 2012). However, this mechanism cannot explain the warming of AA-AABW, since the warming of the Ross Sea dense shelf water is small $\left(2 \times 10^{-3}{ }^{\circ} \mathrm{C}\right.$ decade $\left.^{-1}\right)$ and has been solely attributed to the change in freezing point temperature induced by the rapid freshening (Jacobs and Giulivi, 2010).

Other possible causes of warming include geothermal heat flux, horizontal/vertical diffusion, and reduced supply of cold dense shelf waters. Assessing these candidates in order, we find the average geothermal heat flux for depths of 3500 to $4500 \mathrm{~m}$ is roughly $0.05-0.1 \mathrm{~W} \mathrm{~m}^{-2}$ (Stein and Stein, 1992). Even a $50 \%$ increase would only account for less than $15 \%$ of the warming of AA-AABW and there is no reason to expect the geothermal heat flux to increase rapidly on decadal time-scales. Horizontal diffusion is expected to carry a heat flux of about $0.01 \mathrm{~W} \mathrm{~m}^{-2}$, using a basin-averaged horizontal potential temperature gradient on $\gamma^{n}=28.30 \mathrm{~kg} \mathrm{~m}^{-3}\left(8.9 \times 10^{-7}{ }^{\circ} \mathrm{C} \mathrm{m}^{-1}\right)$ and a horizontal diffusivity of $2 \mathrm{~m}^{2} \mathrm{~s}^{-1}$ (e.g. Ledwell, 1998). This is insignificant relative to the observed warming. Polzin and Firing (1997) estimated a vertical diffusivity of $4.4 \times 10^{-4} \mathrm{~m}^{2} \mathrm{~s}^{-1}$ at $55^{\circ} \mathrm{S}$ on I8S averaged below $1000 \mathrm{~m}$. The basin-averaged vertical potential temperature gradient on $\gamma^{n}=28.30 \mathrm{~kg} \mathrm{~m}^{-3}$ is $3.8 \times 10^{-4}{ }^{\circ} \mathrm{C} \mathrm{m}^{-1}$, implying a vertical diffusive heat flux of $0.67 \mathrm{~W} \mathrm{~m}^{-2}$. Changes in the basin-averaged density stratification, which can affect both horizontal and vertical diffusion, were less than $10 \%$ during the observational period. An increase in vertical diffusion of $10 \%$ would explain only $19 \%$ of the warming over the entire AA-AABW layer. (Density stratification is an important parameter in considering mixing (e.g. Gregg, 1989). As discussed in Sect. 3, changes in the region downstream of the Ross Sea are found to be important, although the change averaged over the entire basin is relatively small.) Overall, none of these processes result in a sufficient change in heat flux to explain the observed warming.

The spatial distribution of the observed changes is also an important factor. While the AA-AABW warmed over most of the basin, cooling was observed near the source region. The fact that localized cooling is accompanied by a decrease in AOU and significant freshening suggests a larger input of the relatively colder, fresher source from the AGVL region relative to the input of relatively warm and salty inflow from the Ross Sea. However, this signal is eroded as AA$\mathrm{AABW}$ flows further downstream. With the above census of 

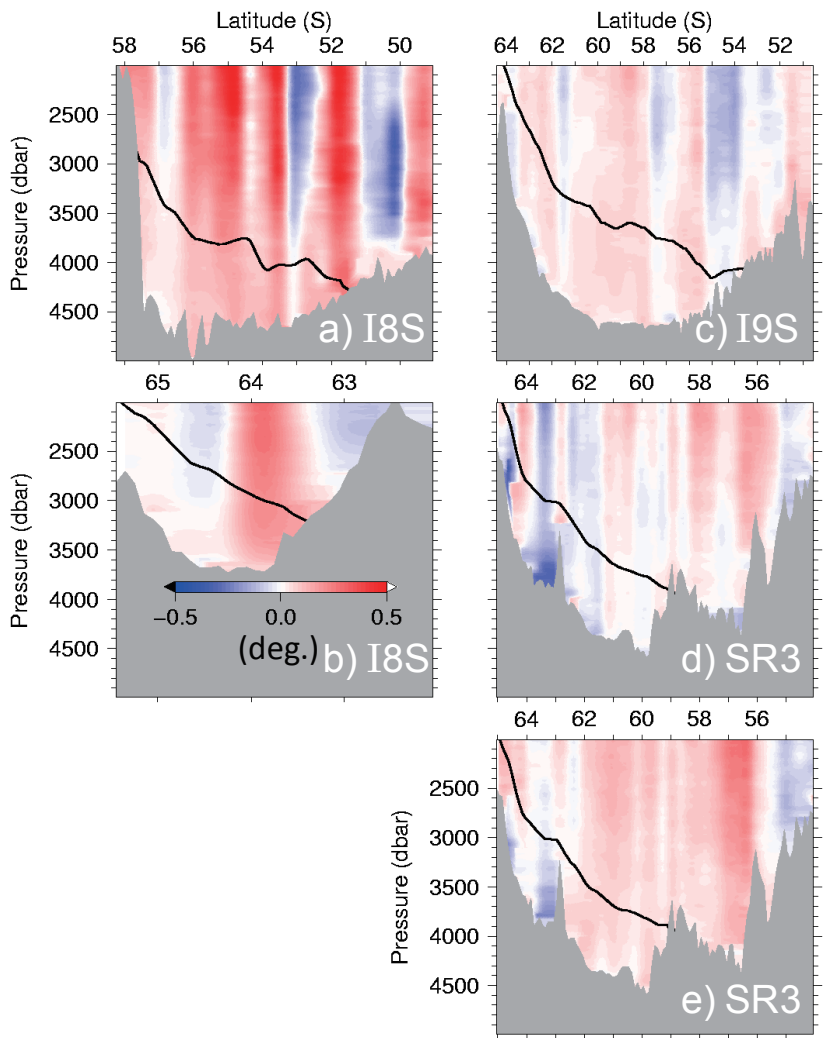

Fig. 4. Difference in isobaric potential temperature between the WHP and repeat occupations. Red areas indicate warming and blue areas indicate cooling. (a) I8S (the Australian-Antarctic Basin), (b) I8S (the PET), (c) I9S, (d) SR3 (obtained from subtracting the WHP from combined repeat occupations in the year 2001, 2002, and 2003), (e) SR3 (obtained from subtracting the WHP from repeat occupations in the year 2008). Mean $\gamma^{n}=28.30 \mathrm{~kg} \mathrm{~m}^{-3}$ isopycnals are shown by solid lines.

potential heat/freshwater sources and the spatial distribution of changes, we hypothesize that a reduction in the inflow of RSBW was the major contributing factor to the changes observed in the AA-AABW. To examine this possibility in more detail, we consider an advective-diffusive balance for the waters between the western Ross Sea and $150^{\circ} \mathrm{E}$.

\section{Advection-diffusion process of RSBW, and its impact on AA-AABW}

\subsection{Changes in RSBW}

The RSBW that supplies the Australian-Antarctic Basin primarily forms on the continental rise of the western Ross Sea from overflows of modified shelf water (hereafter MSW) that originate from the Drygalski Trough and mix with CDW (Gordon et al., 2004, 2009; Orsi and Wiederwohl, 2009). It then migrates westwards around Cape Adare, inshore of the Balleny Islands and into the Australian-Antarctic Basin,
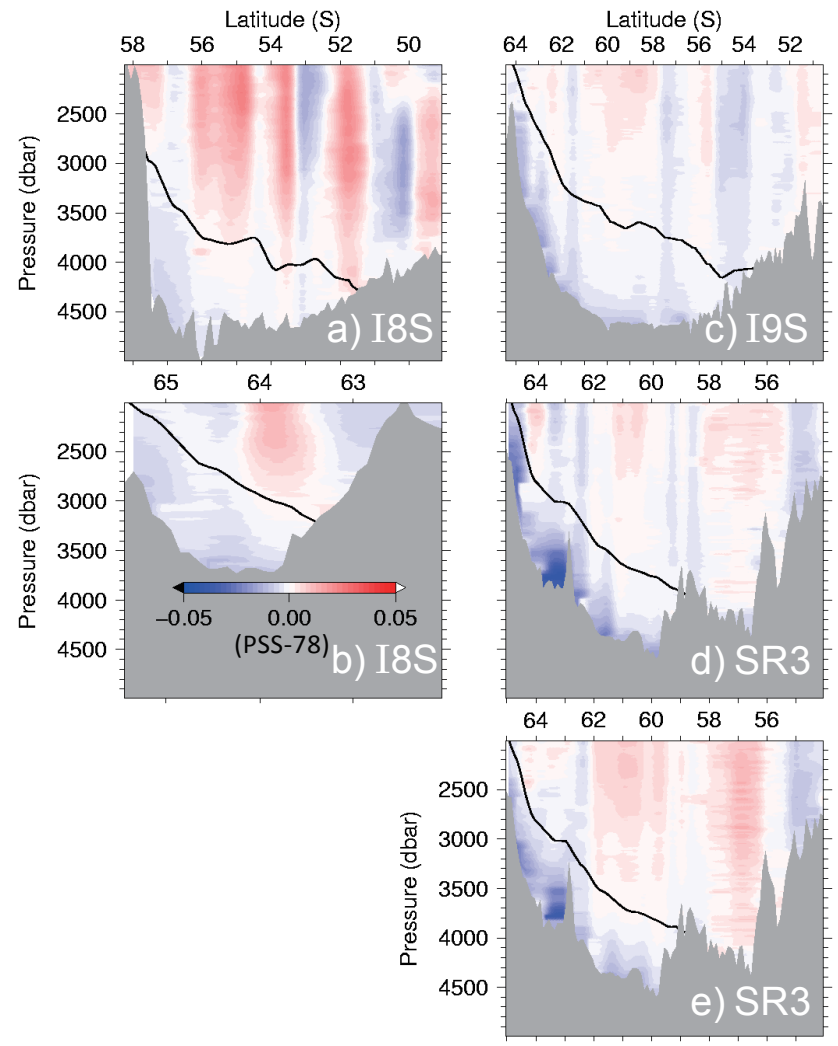

Fig. 5. Difference in isobaric salinity between the WHP and repeat occupations. Red areas indicate increase in salinity and blue areas indicate freshening. (a) I8S (the Australian-Antarctic Basin), (b) I8S (the PET), (c) I9S, (d) SR3 (obtained from subtracting the WHP from combined repeat occupations in the year 2001, 2002, and 2003), (e) SR3 (obtained from subtracting the WHP from repeat occupations in the year 2008). Mean $\gamma^{n}=28.30 \mathrm{~kg} \mathrm{~m}^{-3}$ isopycnals are shown by solid lines.

where it is joined by ALBW after $150^{\circ} \mathrm{E}$. To examine the property changes along this approximate flow path, we extracted summer (January to March) hydrographic profiles between the Drygalski Trough of the Western Ross Sea and $150^{\circ} \mathrm{E}$ from World Ocean Database 2009 (Boyer et al., 2009). A total of 256 profiles that went to within $50 \mathrm{~m}$ of the bottom were available, spanning the period from 1969 to 2004 (Fig. 6d). RSBW freshened consistently from the 1970s and the bottom-intensified salinity maximum was strongly attenuated in the 2000s throughout the study area around $150^{\circ} \mathrm{E}$ (Fig. 6a), $160^{\circ} \mathrm{E}$ (Fig. 6b), and in the vicinity of the source region (Fig. 6c). Wide-spread warming is observed throughout the flow path of the RSBW except just near the source region (within $300 \mathrm{~km}$ from the Drygalski Trough). Thus, upstream of the AGVL region, where it is not affected by the inflow of ALBW, the situation is somewhat different from the downstream region where the cooling signal is obtained (SR3, southern I9S). At $160^{\circ} \mathrm{E}$, AOU averaged over the $100-\mathrm{m}$ thick layer at the bottom slightly increased 

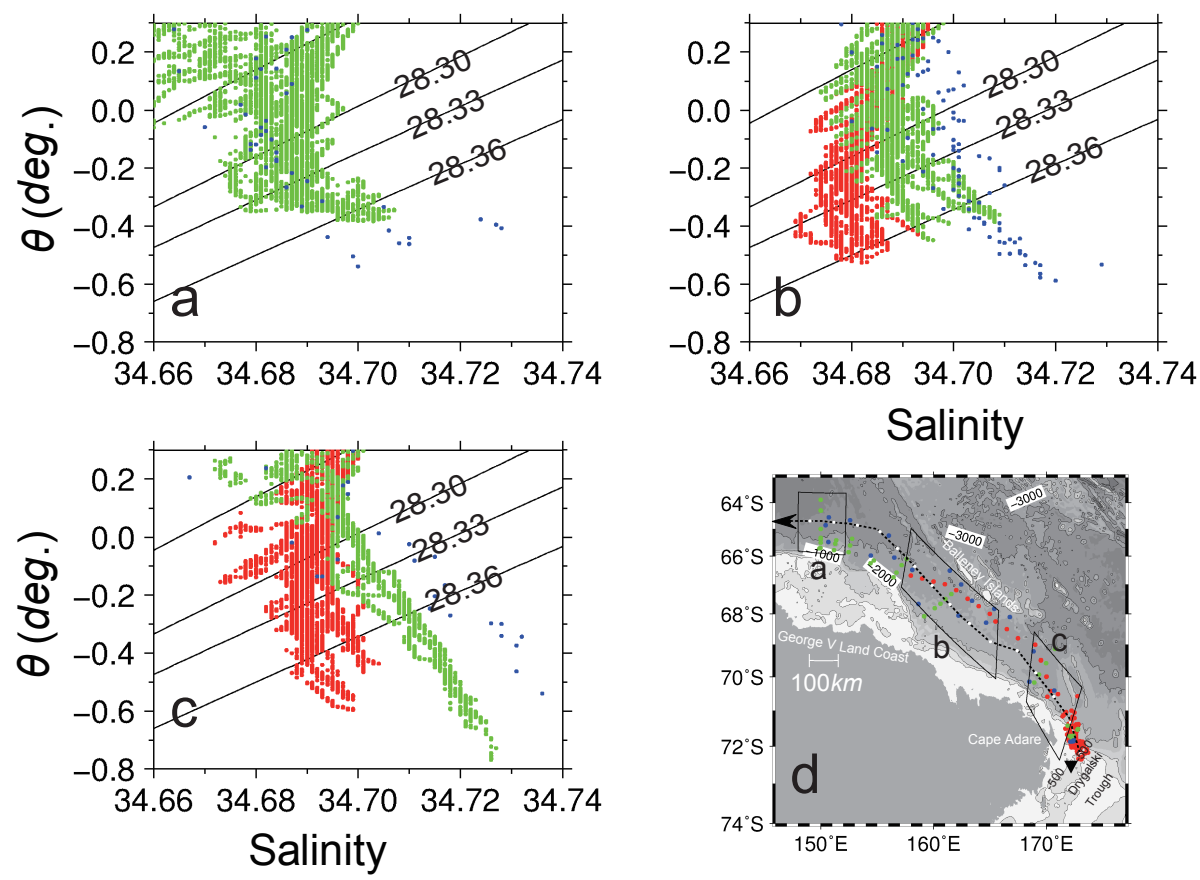

Fig. 6. $\theta$ - $S$ diagrams of region between the Drygalski Trough and $150^{\circ}$ E. (a) around $150^{\circ} \mathrm{E}$, (b) around $160^{\circ} \mathrm{E},(\mathbf{c})$ immediately downstream of the Ross source region, (d): locations of stations. Blue circles are from occupations in the 1970s, green circles are from 1990s and red circles are from 2000s. Labeled black lines in (a), (b), and (c) are contour of neutral density $\left(\mathrm{kg} \mathrm{m}^{-3}\right)$. Dashed arrow in (d) indicates approximate position of flow path of the RSBW and white circles are marked on $100 \mathrm{~km}$ interval.

in the 2000s $(118.1 \mu \mathrm{mol} \mathrm{kg}-1)$ compared to that in $1970 \mathrm{~s}$ (114.1 $\mu$ mol kg ${ }^{-1}$; not shown). The freshening of RSBW can be explained by freshening of its dense water source, but not its warming $\left(2 \times 10^{-3}{ }^{\circ} \mathrm{C}\right.$ decade $\left.^{-1}\right)$. However a decrease in volume transport of RSBW reduces the supply of both cold and oxygen rich water throughout its flow path, consistent with the property changes between the Drygalski Trough and $150^{\circ} \mathrm{E}$.

To examine the flow regime and derive the temporal change of RSBW, the mixing process is studied using Optimum Multiparameter analysis (OMP) to calculate the relative contributions to RSBW of the dense shelf water exported from the Drygalski Trough (hereinafter termed High Salinity Shelf Water, HSSW) and the Lower Circumpolar Deep Water (LCDW). See Appendix A for details. In both the 1970s and 2000s, most of the profiles in the upstream region within $150 \mathrm{~km}$ (east of $171^{\circ} \mathrm{E}$ ) of the Drygalski Trough showed high HSSW fractions $>0.4$ (Fig. 7). In the downstream region beyond $150 \mathrm{~km}$, it is less than 0.2 . This rapid decrease suggests that the intensive mixing process including entrainment governs the properties of MSW, i.e. the mid-slope precursor to $A A B W$, within the upstream region, and that the final properties of RSBW become stable at around $150 \mathrm{~km}$ downstream. Thus, the upstream region less than $150 \mathrm{~km}$ from the Drygalski Trough is categorized as the region of the intensive modification/formation of MSW into RSBW and the downstream region beyond $150 \mathrm{~km}$ is categorized as the flow path of RSBW after vigorous mixing. Hereafter, the former region is referred to as the modification path of MSW and the latter to as the flow path of RSBW.

The availability of observational data is important. Along the modification path of the MSW, profiles showing low HSSW fractions are mostly from the 2000s. Although this may reflect decreased HSSW export in the 2000s, the spatial density of the profiles is extremely low in the 1970s compared to that of the 2000s. To avoid an error due to this spatial aliasing, we only analyze the flow path of the RSBW where the spatial density of the profiles is equivalent between the 1970s and 2000s. We will further exclude the region beyond $900 \mathrm{~km}$ (west of $158^{\circ} \mathrm{E}$ ) from the Drygalski Trough where there are no observations in the 2000s. Hence, we consider changes in RSBW along its flow path in the region 150$900 \mathrm{~km}\left(171-158^{\circ} \mathrm{E}\right)$ from the Drygalski Trough, between the 1970 s and 2000s.

\subsection{An advection-diffusion model of RSBW transport}

We will now consider the mixing process along the flow path of RSBW from 171 to $158^{\circ} \mathrm{E}$ (i.e. between $150-900 \mathrm{~km}$ from its source region in the Drygalski Trough). Along this region, the RSBW flows westward along the upper continental rise (Fig. 6d). Considering the relatively smooth topography in this region (e.g. Fig. 8), the RSBW is expected to be undergo relatively weaker background mixing. Here we use a 


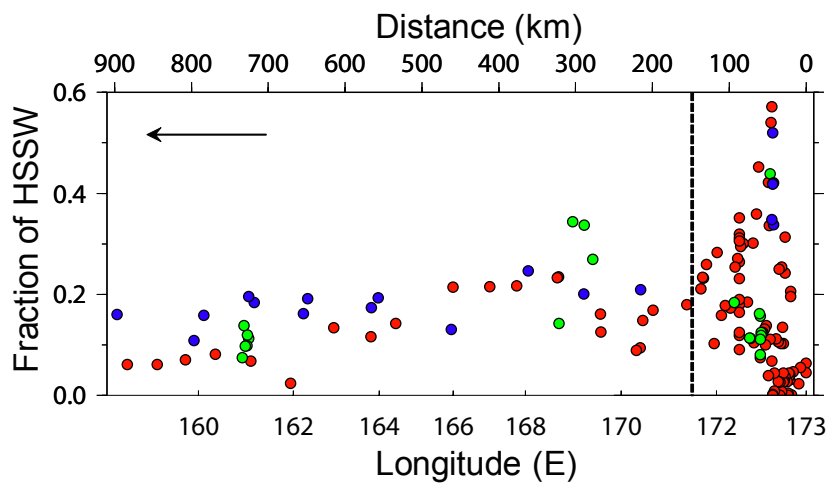

Fig. 7. Distribution of fraction of the HSSW within $100 \mathrm{~m}$ from bottom along flow path of the RSBW estimated by OMP analysis. Blue circles are from occupations in the 1970s, green circles are from 1990s and red circles are from 2000s. An arrow indicates downstream direction of RSBW and vertical dashed line separates modification path of MSW and flow path of RSBW. See text for definition of paths.

simple model to analyze the long-term changes in advectiondiffusion processes of the RSBW in this sector.

The governing diffusion equation of the potential temperature of RSBW can be written as follows.

$\theta_{\mathrm{t}}+u \theta_{\mathrm{x}}+v \theta_{\mathrm{y}}+w \theta_{\mathrm{z}}=\frac{\partial}{\partial x} K_{\mathrm{h}} \theta_{\mathrm{x}}+\frac{\partial}{\partial y} K_{\mathrm{h}} \theta_{\mathrm{y}}+\frac{\partial}{\partial z} K_{\mathrm{z}} \theta_{\mathrm{z}}$,

where $x$ is the flow path coordinate (downstream positive), $y$ is the direction orthogonal to the flow path, and $z$ is the vertical axis (upward positive). $K_{\mathrm{Z}}$ and $K_{\mathrm{h}}$ are the vertical and horizontal diffusivities, respectively, with subscripts indicating the first order derivatives.

Starting from this general formula, we will simplify this equation based on the settings and approximations applicable in this case. As shown in Fig. 8, the flow path of the RSBW is bounded by the continental slope and sea floor in the direction of $y$ and $z$, respectively, and the fluxes through these two boundaries are zero. Hence, the horizontal diffusion term of the $y$-axis and the vertical diffusion term are replaced by the fluxes from the other side divided by the width $L o$ and thickness $H$ of RSBW, respectively.

$\theta_{\mathrm{t}}+u \theta_{\mathrm{x}}+v \theta_{\mathrm{y}}+w \theta_{\mathrm{z}}=\frac{\partial}{\partial x} K_{\mathrm{h}} \theta_{\mathrm{x}}+\frac{1}{L o} K_{\mathrm{h}} \theta_{\mathrm{y}}+\frac{1}{H} K_{\mathrm{z}} \theta_{\mathrm{z}}$.

The third and fourth terms on the left hand side can be neglected since the velocity orthogonal to the flow path and the vertical velocity are negligible. The first term on the right hand side can be neglected because the horizontal gradient in the $\mathrm{x}$-direction is negligible compared to gradients in the $\mathrm{y}$ and z-directions. Equation (1) can therefore be simplified to:

$\theta_{\mathrm{t}}+u \theta_{\mathrm{x}}=\frac{1}{L o} K_{\mathrm{h}} \theta_{\mathrm{y}}+\frac{1}{H} K_{\mathrm{z}} \theta_{\mathrm{z}}$.
Here, we will consider the relative importance of the first and second terms on the right hand side. From Fig. 8, the width $L o$ and thickness $H$ of the RSBW can be estimated as $200 \mathrm{~km}$ and $200 \mathrm{~m}$, respectively, and the horizontal and vertical gradients were estimated as $\theta_{\mathrm{y}} \approx 2.6 \times 10^{-6}{ }^{\circ} \mathrm{C} \mathrm{m}^{-1}$ and $\theta_{\mathrm{z}} \approx 7.0 \times 10^{-4}{ }^{\circ} \mathrm{C} \mathrm{m}^{-1}$, respectively. Setting the vertical diffusivity is a challenge because it has not been determined for this study area. Muench et al. (2009) estimated it in the vicinity of the Drygalski Trough but not for the remaining area downstream. However, Kunze et al. (2006) estimated an average vertical diffusivity for the Southern Ocean by using the strain from CTD profiles and the vertical velocity shear from Lowered acoustic Doppler current profiler. From Fig. 16 of Kunze et al. (2006), the near bottom vertical diffusivity can be in the orders of between $10^{-5}-10^{-4} \mathrm{~m}^{2} \mathrm{~s}^{-1}$. Adopting Osborn's (1980) model, vertical diffusivity $K_{\mathrm{Z}}$ can be written in the form of

$K_{\mathrm{Z}}=0.2 \frac{\varepsilon}{N^{2}}$,

where 0.2 is the mixing efficiency, $\varepsilon$ is the energy dissipation rate, and $N$ is the Brunt-Väisälä frequency. Here, we simply assume that $\varepsilon$ to be constant over decadal or longer timescale since the energy provided to larger spatial scale motion (e.g. tides), which provides energy to turbulence, is constant (note-validity of this assumption will be discussed later). $N^{2}$ can be calculated from observed vertical profiles using

$N^{2}=g\left(\beta S_{\mathrm{Z}}-\alpha \theta_{\mathrm{z}}\right) \because g=-9.8 \mathrm{~ms}^{-2}$,

where $\alpha$ is the thermal expansion rate and $\beta$ is the saline contraction rate. With the assumption of constant $\varepsilon$, the rate of temporal change in $K_{\mathrm{z}}$ can be estimated by calculating $N^{2}$ for each period. Here, by using the vertical diffusivity of Kunze et al. (2006), the vertical flux has a value of $3.5 \times 10^{-11}-3.5 \times 10^{-10}{ }^{\circ} \mathrm{C} \mathrm{s}^{-1}$. By using $K_{\mathrm{h}}=2 \mathrm{~m}^{2} \mathrm{~s}^{-1}$ (e.g. Ledwell, 1998), horizontal flux takes value of $2.6 \times$ $10^{-11 \circ} \mathrm{C} \mathrm{s}^{-1}$. Hence, the vertical diffusion term is likely to be one order of magnitude larger than the horizontal diffusion term. Therefore we neglect the horizontal diffusion term to obtain the formula as

$\theta_{\mathrm{t}}+u \theta_{\mathrm{x}}=\frac{1}{H} K_{\mathrm{z}} \theta_{\mathrm{z}}$

Now we will consider the uniform current $(u>0)$ along the flow path of RSBW. There is no direct observation of $u$, but Fukamachi et al. (2000) measured current speed of 14.1 to $19.8 \mathrm{~cm} \mathrm{~s}^{-1}$ at $140^{\circ} \mathrm{E}$, slightly downstream of the current region of focus. If we assume the above value for the RSBW current speed, the advection time of its signal along the $750 \mathrm{~km}$ of its flow path is 42 to 62 days. For the time scale of multi-decadal variability, temperature variations in both time and space in this region are in the order of $0.1^{\circ} \mathrm{C}$, and, hence, our formula becomes

$\frac{\theta_{\mathrm{z}}}{\theta_{\mathrm{x}}}=\frac{u H}{K_{\mathrm{z}}}$ 

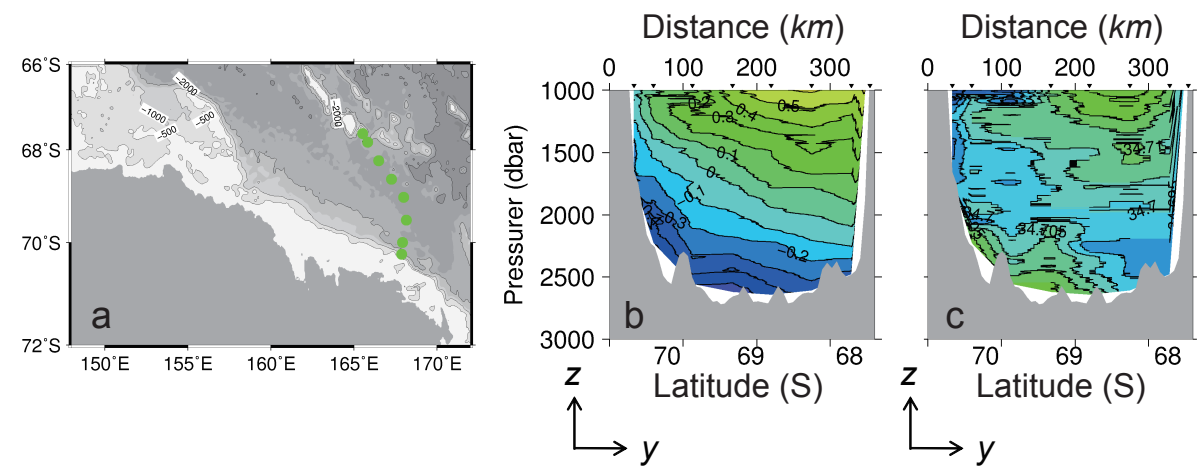

Fig. 8. Thickness and width (cross shore) of the RSBW from occupations in the 1990s. (a) Location of stations, (b) vertical cross section of potential temperature, (c) vertical cross section of salinity. $y$ is cross shore coordinate (offshore positive), and $z$ is vertical axis (upward positive). Thickness and width of cold and saline the RSBW are approximately $200 \mathrm{~m}$ and $200 \mathrm{~km}$, respectively.

for each period of interest. The assumed current speeds are likely faster than the RSBW due to the input of ALBW at $\sim 142^{\circ}$ E. However, even if we assume a half of the current speed, the scaling that $\theta_{\mathrm{t}}$ is negligible remains valid. Given Eq. (5), we can estimate the volume transport $u H$ for a certain period by estimating $\theta_{\mathrm{x}}, \theta_{\mathrm{z}}$, and $N^{2}$ based on the observed hydrographic profiles, and thereafter the decadal change of $u H$ can also be obtained.

Note that Eq. (5) implies that the ratio of the vertical gradient to the horizontal gradient is determined by the ratio of the volume transport to the vertical diffusivity. Horizontal velocity $u$ is relevant to the residence time in the benthic box, and a large $u$ acts to enhance the contrast between the RSBW layer and overlying water, i.e. producing a larger vertical gradient. Thickness $H$ determines the total volume of the RSBW, and hence a larger $H$ acts to enhance the vertical gradient between the RSBW and overlying layers. Hence, when the volume transport $u H$ is large, the vertical gradient $\theta_{\mathrm{z}}$ should be large (and/or horizontal gradient $\theta_{\mathrm{x}}$ should be small). If $u H$ is small, $\theta_{\mathrm{Z}}$ is small (and/or $\theta_{\mathrm{x}}$ is large). Conversely, large vertical diffusivity $K_{\mathrm{Z}}$ tends to reduce the vertical gradient and thus, acts in the opposite sense to $u H$.

The diffusion equation for salinity is also given in this manner. Then, Eq. (5) is expressed as

$u H=K_{\mathrm{z}} \frac{\theta_{\mathrm{z}}}{\theta_{\mathrm{x}}}=K_{\mathrm{z}} \frac{S_{\mathrm{z}}}{S_{\mathrm{x}}}$

By substituting Eq. (3) into Eq. (6), we have the following equation.

$u H^{*}=\frac{1}{N^{2}} \frac{\theta_{\mathrm{z}}}{\theta_{\mathrm{x}}}=\frac{1}{N^{2}} \frac{S_{\mathrm{z}}}{S_{\mathrm{x}}}$

where $u H^{*}=u H / 0.2 \varepsilon$. In the next subsection, we discuss change of volume transport by applying Eq. (7) to each respective period.

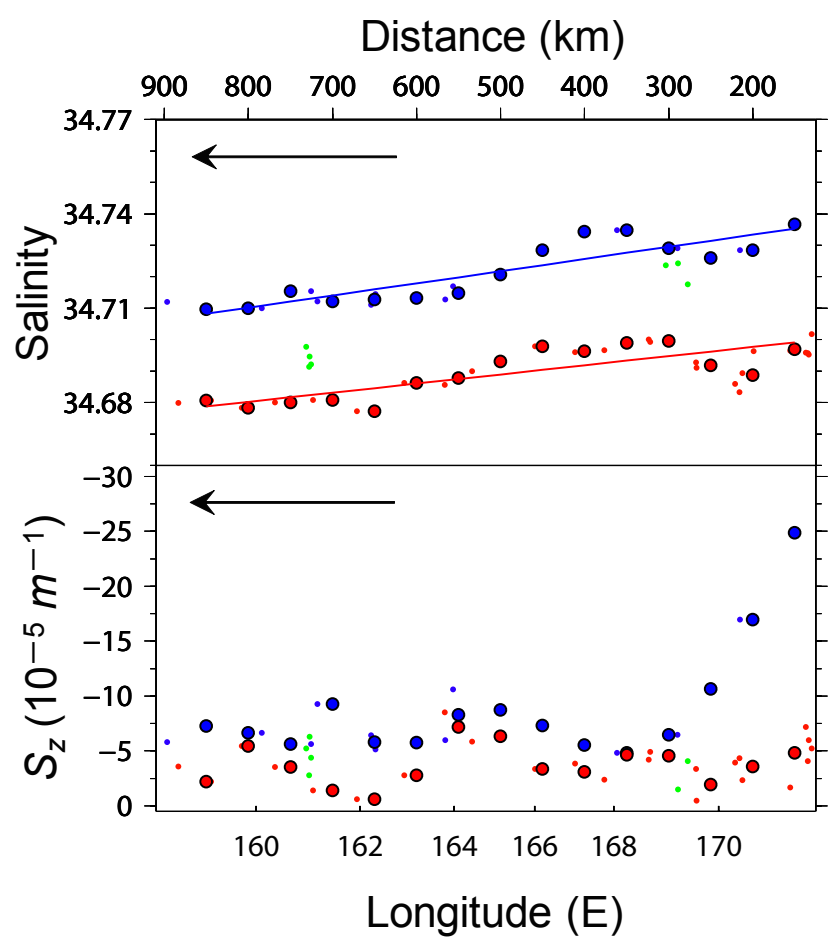

Fig. 9. Distribution of salinity averaged over the $100 \mathrm{~m}$-thick layer at the bottom (upper panel) and vertical salinity gradient (lower panel) along flow path of the RSBW. Small circles are from occupations in the 1970s (blue), 1990s (green) and 2000s (red). In the estimation of vertical gradient, vertical gradients of $150 \mathrm{~m}$ scale are calculated at every $1 \mathrm{~m}$ interval by linear least square fit for each profile. The largest vertical gradients within $300 \mathrm{~m}$ from bottom are adopted as vertical gradient formed between the RSBW and the ambient water. Large circles are bin averages for the 1970s and 2000s and same colors as those for small circles are given. Solid lines in upper panel are regression lines for bin averages in region between $150 \mathrm{~km}$ and $900 \mathrm{~km}$ downstream from the Drygalski Trough. Arrows in both panels indicate downstream direction of RSBW. 


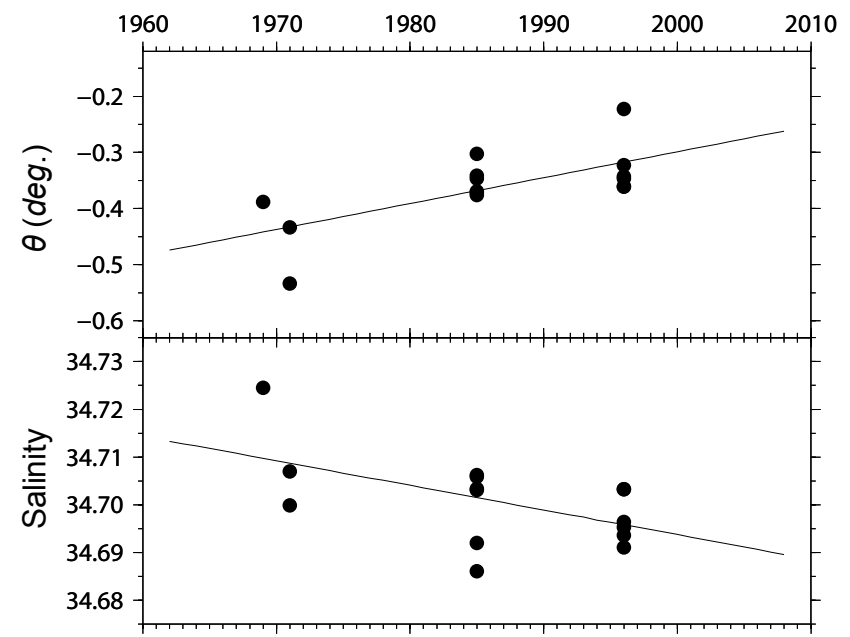

Fig. 10. Potential temperature (upper panel) and salinity (lower panel) averaged over the $100 \mathrm{~m}$-thick layer at the bottom vs. year with regression lines from region around $150^{\circ} \mathrm{E}$. Profiles locate within box (a) in Fig. 6d are used here.

Table 3. Mean vertical salinity gradients, horizontal salinity gradients, their ratios, $N^{2}$ and $u H^{*}$ for the RSBW in the 1970s and 2000 s from region between $150 \mathrm{~km}$ and $900 \mathrm{~km}$ downstream from the Drygalski Trough.

\begin{tabular}{lll}
\hline & $1970 \mathrm{~s}$ & $2000 \mathrm{~s}$ \\
\hline$S_{\mathrm{Z}}\left(\mathrm{m}^{-1}\right)$ & $-8.94 \pm 0.71 \times 10^{-5}$ & $-3.71 \pm 0.24 \times 10^{-5}$ \\
$S_{\mathrm{X}}\left(\mathrm{m}^{-1}\right)$ & $-3.86 \pm 0.59 \times 10^{-8}$ & $-2.90 \pm 0.62 \times 10^{-8}$ \\
$S_{\mathrm{Z}} / S_{\mathrm{X}}$ & $2300 \pm 400$ & $1300 \pm 300$ \\
$N^{2}\left(\mathrm{~s}^{-2}\right)$ & $1.91 \pm 0.17 \times 10^{-6}$ & $1.34 \pm 0.05 \times 10^{-6}$ \\
$u H^{*}\left(\mathrm{~s}^{2}\right)$ & $12.1 \pm 2.3 \times 10^{8}$ & $9.5 \pm 2.2 \times 10^{8}$ \\
\hline
\end{tabular}

\subsection{Changes in the advection-diffusion process of RSBW}

The data along the flow path of RSBW into the AustralianAntarctic Basin $\left(171-158^{\circ} \mathrm{E}\right.$, i.e. downstream region between 150-900 km from the Drygalski Trough) are used to examine change in the volume transport of RSBW between the 1970s and 2000s. In practice, the relative contribution of the large-scale pattern and small-scale variability along the flow path of the RSBW are different for temperature and salinity near the source region. While the large-scale pattern of temperature and its gradient are subject to significant small-scale perturbations, those of salinity and its gradient are dominant over small-scale spatial variations. This tendency becomes more prominent in the 2000s because the salinity contrast between the ambient water is reduced over this period due to the freshening of the RSBW, while the potential temperature contrast remained relatively unchanged. Hence, we conduct further analysis based on salinity aver- aged over the 100-m thick layer at the bottom and vertical gradients (Fig. 9).

We will now focus on the treatment of data and their application to the model. To ensure all the areas are uniformly weighted, horizontal gradients were estimated by a least squares fit to the data averaged in $50 \mathrm{~km}$ interval bins for the two periods. Horizontal gradients of salinity in the $1970 \mathrm{~s}$ and $2000 \mathrm{~s}$ are estimated as $-3.86 \pm 0.59 \times 10^{-8} \mathrm{~m}^{-1}$ and $-2.90 \pm 0.62 \times 10^{-8} \mathrm{~m}^{-1}$, respectively (Table 3 ). Thus, the change in horizontal gradient from the 1970s to 2000s is estimated to present a $\sim 25 \%$ decrease. Vertical gradients in 1970s and 2000s are estimated by taking the mean of bin averages (i.e. the mean of the larger circles in the lower panels of Fig. 9) as $-8.94 \pm 0.71 \times 10^{-5} \mathrm{~m}^{-1}$ and $-3.71 \pm 0.24 \times 10^{-5} \mathrm{~m}^{-1}$, respectively. The change in vertical gradient by far exceeds that of the horizontal gradient and is estimated as a $\sim 59 \%$ decrease. Accordingly, the ratios of vertical to horizontal gradient in 1970s and 2000s are estimated as $2300 \pm 400$ and $1300 \pm 300$, respectively, and present a decrease of $\sim 45 \%$. From Eq. (4), $N^{2}$ in 1970s and $2000 \mathrm{~s}$ are $1.91 \pm 0.17 \times 10^{-6} \mathrm{~s}^{-2}$ and $1.34 \pm 0.05 \times 10^{-6} \mathrm{~s}^{-2}$ respectively, and as such is a $\sim 30 \%$ decrease. Substituting these estimates for Eq. (7), $u H^{*}$ in the 1970s and 2000s are estimated as $12.1 \pm 2.3 \times 10^{8} \mathrm{~s}^{2}$ and $9.5 \pm 2.2 \times 10^{8} \mathrm{~s}^{2}$, respectively. Hence, the temporal change in $u H^{*}$ from the 1970s to the 2000 s is estimated as a decrease of $21 \pm 23 \%$, although it is subjected to a large uncertainty.

These results suggest a reduction in the volume transport of the RSBW is associated with enhanced vertical diffusion, as a result of weakening in the stratification (the decrease in $N^{2}$ is sufficient to increase the vertical diffusivity by $42 \%$ ). A reduction in volume transport is also consistent with the observed warming and increase in AOU of the RSBW.

\subsection{Impact of RSBW on AABW in the Australian- Antarctic Basin}

The property changes of the RSBW are evident from the observations (Sect. 3.1) and a decrease in its volume transport is also suggested (Sects. 3.2-3.3). Now we examine the influence of both of these processes on the bottom water properties in the basin as a whole (AA-AABW), using a simple box model under some realistic assumptions.

The change in potential temperature of the AA-AABW, due to the supply of RSBW per unit time, can be represented as

$-\frac{1}{V} V_{\mathrm{tr}} \Delta \theta$

where $V_{\text {tr }}$ is volume transport of the RSBW supplied to the Australian-Antarctic Basin, $\Delta \theta$ is difference in potential temperature between the RSBW and the AA-AABW, and $V$ is total volume of the AA-AABW. Here, $V_{\text {tr }}$ and $\Delta \theta$ are expressed as the sum of the steady state component and its fluctuation which is assumed to increase in proportion to 
time, i.e., $V_{\mathrm{tr}}=\overline{V_{\mathrm{tr}}}+\delta V_{\mathrm{tr}} t$ and $\Delta \theta=\overline{\Delta \theta}+\delta \theta t$. Substitution of these into Eq. (8) gives,

$-\frac{1}{V}\left(\overline{V_{\mathrm{tr}} \Delta \theta}+\overline{V_{\mathrm{tr}}} \delta \theta t+\overline{\Delta \theta} \delta V_{\mathrm{tr}} t+\delta \theta \delta V_{\mathrm{tr}} t^{2}\right)$.

The first term in the brackets is the steady state component, which is assumed to be balanced with the steady state heat flux in the basin due to vertical and horizontal diffusion and geothermal heat. $V$ is kept constant in this formulation (see Sect. 4). Here we are interested in the fluctuation components that deviate from the balance, and thus, we neglect the first term and the fourth infinitesimal term. By integrating the above equation with respect to time, the warming of the AAAABW due to the RSBW influence ( $\Delta \theta_{\mathrm{RSBW}}$ ) by temporal changes in property and volume transport can be considered. The corresponding freshening of the AA-AABW due to the RSBW influence ( $\left.\Delta S_{\mathrm{RSBW}}\right)$ is also given by the same procedure. For the integrating time $T$, we now have

$$
\begin{aligned}
\Delta \theta_{\mathrm{RSBW}} & =-\frac{1}{V}\left(\overline{V_{\mathrm{tr}}} \delta \theta+\overline{\Delta \theta} \delta V_{\mathrm{tr}}\right) \frac{T^{2}}{2} \\
\Delta S_{\mathrm{RSBW}} & =-\frac{1}{V}\left(\overline{V_{\mathrm{tr}}} \delta S+\overline{\Delta S} \delta V_{\mathrm{tr}}\right) \frac{T^{2}}{2}
\end{aligned}
$$

The first term on the right hand side of Eq. (10) is the component due to the changes in property of the RSBW and the second term is the component due to the decrease in its volume transport.

The contributions of temperature and salinity changes from the RSBW are then estimated using Eq. (10) for the 10 year period from 1995 to 2005, following the observational period in the Australian-Antarctic Basin. The trend in potential temperature and salinity of the RSBW is evaluated using the regression lines for the bottom water properties averaged over a $100 \mathrm{~m}$-thick bottom layer around $150^{\circ} \mathrm{E}$ (Fig. 10). The potential temperature and salinity of the AAAABW in the years 1995 and 2005 are calculated as a basin average estimated using all data shown in Table 1 and the trends shown in Table 2a, respectively. These averages are estimated by the same interpolation procedure as that in Sect. 2.1. Then, $\delta \theta$ and $\delta S$, the changing rate of difference between the RSBW and the AA-AABW, are estimated as

$\delta \theta=\frac{\Delta \theta_{2005}-\Delta \theta_{1995}}{T}, \quad \delta S=\frac{\Delta S_{2005}-\Delta S_{1995}}{T}$

The steady state component of the RSBW volume transport $\overline{V_{\text {tr }}}$ is required in this formulation. Here we use $7 \mathrm{~Sv}$ as a reference with an average westward velocity of $17.5 \mathrm{~cm} \mathrm{~s}^{-1}$ over the area of width and thickness of $200 \mathrm{~km}$ and $200 \mathrm{~m}$, respectively, at $150^{\circ} \mathrm{E}$ (note - the validity of this estimate will be discussed later).

With the above $\overline{V_{\text {tr }}}$ and observed $\delta \theta$ and $\delta S$, the change in property of the RSBW can explain $44 \pm 5 \%$ and $63 \pm 8 \%$ of observed warming and freshening of the AA-AABW. The change rate of volume transport $\delta V_{\text {tr }}$ is the largest unknown
Table 4. Possible warming and freshening of the AA-AABW induced by change in property, decrease in volume transport of the RSBW, and their summations under the two scenarios of volume transport decrease of $6.7 \% / 10$ years and $20 \% / 10$ years. Results are shown in the form of ratio to the overall warming and freshening of the AA-AABW estimated in Sect. 2. Subscripts "1" denote contribution by change in property (first term in right hand side of Eq. 10) and subscript "2" denote contribution by decrease in volume transport of the RSBW (second term in right hand side of Eq. 10).

\begin{tabular}{lcc}
\hline & Scenario 1 $(6.7 \%)$ & Scenario 2(20\%) \\
\hline$\Delta \theta_{\mathrm{RSBW}} 1$ & $44 \pm 5 \%$ & $44 \pm 5 \%$ \\
$\Delta \theta_{\mathrm{RSBW}} 2$ & $6 \pm 1 \%$ & $19 \pm 2 \%$ \\
$\Delta \theta_{\mathrm{RSBW}}$ & $51 \pm 6 \%$ & $63 \pm 8 \%$ \\
$\Delta S_{\mathrm{RSBW}} 1$ & $61 \pm 8 \%$ & $61 \pm 8 \%$ \\
$\Delta S_{\mathrm{RSBW}} 2$ & $23 \pm 3 \%$ & $69 \pm 9 \%$ \\
$\Delta S_{\mathrm{RSBW}}$ & $84 \pm 10 \%$ & $131 \pm 16 \%$ \\
\hline
\end{tabular}

in Eq. (10). Hence, we consider possible two scenarios. In scenario 1 , we assume that there was a $6.7 \%$ decrease in the volume transport of the RSBW from 1995 to 2005. This value is based on the suggested decrease in volume transport of the RSBW $(\approx 20 \% / 30$ years) derived in Sect. 3.2. For the scenario 2, we assume a $20 \%$ decrease of RSBW volume transport, which reflects the rapid decrease in sea ice production described by Tamura et al. (2008) over this period.

Hereafter we evaluate $\Delta \theta_{\mathrm{RSBW}}$ and $\Delta S_{\mathrm{RSBW}}$ using Eq. (10) according to these two scenarios for the decrease in volume transport (Table 4). For scenario $1, \Delta \theta_{\mathrm{RSBW}}$ can explain $51 \pm 6 \%$ of the overall warming of the AA-AABW. The contribution of the change in property (first term) by far exceeds that of the change in volume transport (second term). $\Delta S_{\mathrm{RSBW}}$ can explain $84 \pm 10 \%$ of the overall freshening of the AA-AABW and similar to the case of the $\Delta \theta_{\mathrm{RSBW}}$, the contribution of the first term by far exceeds that of the second term. For scenario 2, the second term largely increased and $\Delta \theta_{\mathrm{RSBW}}$ and $\Delta S_{\mathrm{RSBW}}$ would explain $63 \pm 8 \%$ and $131 \pm 16 \%$ of the overall warming and freshening, respectively. In this scenario, the contribution of the second term is comparable to that of the first term for the freshening, while it is approximately only a half of the first term for the warming.

Hence, the change in RSBW properties can explain nearly a half of the observed change of the AA-AABW, and the decrease in RSBW volume transport can also be significant, especially for a larger decrease with time.

\section{Discussion}

The property changes observed in the AA-AABW require a heat and freshwater input of $1300 \pm 200 \mathrm{GW}$ and $24 \pm$ $3 \mathrm{Gt} \mathrm{year}^{-1}$, respectively (Sect. 2). The inferred rate of warming $\left(0.37 \pm 0.05 \mathrm{~W} \mathrm{~m}^{-2}\right)$ of the AA-AABW that supplies the abyssal basin deeper than $3000 \mathrm{~m}$ is comparable to that of the 
world ocean warming $\left(0.20 \mathrm{~W} \mathrm{~m}^{-2}\right)$ between 1955 and 1998 (Levitus et al., 2005), a large part of which occurs above $700 \mathrm{~m}$ depth. The observed freshening is about half of the freshening rate on the shelf and over the Ross Sea gyre reported by Jacobs et al. (2002). Errors are estimated from the multiple occupations of SR3 at $140^{\circ} \mathrm{E}$, as only one repeat of the other sections is available. There would be potential errors due to temporal aliasing of higher-frequency signals such as the spring-neap tidal cycles (e.g. Whitworth and Orsi, 2006). However, most of the WHP sections used here are located well away from the dense shelf water source region, and, even near the source region, one-year mooring observations (e.g. Fukamachi et al., 2000; Williams et al., 2010) show relatively small signal of the Fortnightly tides in summer. Hence the effect of such aliasing was not considered here, although it needs further quantitative discussions based on continuous direct observations such as moorings. The estimates of the section and basin-wide changes (Table 2) are calculated in the fixed volume of water below the depth of the mean $\gamma^{n}=28.30 \mathrm{~kg} \mathrm{~m}^{-3}$ isopycnal. The thickness of AA-AABW layer decreases with time due to both warming and freshening. However, the decrease is not significant (estimated as 11-14\%/10 year on 3 sections) and, thus, does not have a large impact on the estimation of Eq. (10), i.e. it increases the estimated contributions from RSBW only by $10 \%$. Hence, the effect of change in the volume of AAAABW is neglected in Sect. 3.4.

Changes in the RSBW are inferred to be one of the major factors driving the changes observed in the AA-AABW (Sect. 3). Both the enhanced vertical diffusion as a result of a weakening stratification and a decrease in RSBW volume transport are likely to contribute to the warming and increase in AOU of the RSBW along its flow path, and hence to the changes in AA-AABW observed downstream. However, this conclusion rests on numerous assumptions and here we discuss the robustness and consistency of these results.

Firstly, horizontal diffusion was assumed to be small (Eq. 2). We test the validity of this approach by confirming consistency between the observed vertical diffusivity (Muench et al., 2009) and that which we adopted in this study. Based on Eq. (6), $K_{\mathrm{Z}}$ can be expressed as:

$K_{\mathrm{z}}=\frac{u H}{\theta_{\mathrm{z}} / \theta_{\mathrm{x}}}=\frac{u H}{S_{\mathrm{z}} / S_{\mathrm{x}}}$.

$u H$ can be estimated as $19.6 \mathrm{~m}^{2} \mathrm{~s}^{-1}$ based on the dense shelf water export from the Drygalski Trough of $0.98 \mathrm{~Sv}$ (Whitworth and Orsi, 2006) and a $50 \mathrm{~km}$ width for the Drygalski Trough. By using values of $S_{\mathrm{Z}} / S_{\mathrm{X}}$ in the $1970 \mathrm{~s}$ and $2000 \mathrm{~s}$, our adopted $K_{\mathrm{z}}$ can be estimated as $0.84 \times 10^{-2} \mathrm{~m}^{2} \mathrm{~s}^{-1}$ and $1.53 \times 10^{-2} \mathrm{~m}^{2} \mathrm{~s}^{-1}$, respectively. These values are consistent with the order $\left(10^{-2}-10^{-3} \mathrm{~m}^{2} \mathrm{~s}^{-1}\right)$ observed in the vicinity of the Drygalski Trough by Muench et al. (2009). This suggests that the observed changes in property along the flow path can be explained by vertical flux alone and does not require other flux sources. Hence, we expect that our assump- tion for neglecting horizontal diffusion will not detract from our result. However, due to the lack of direct observations of both the vertical diffusivity and volume transport further downstream, it is difficult to fully examine this problem.

Secondly, the energy dissipation rate $\varepsilon$ was assumed to be constant (Eq. 3) since it is expected that the energy provided to larger spatial scale motion is constant. This assumption is considered to be applicable because, even if it is quantitatively unreasonable, the inference that vertical diffusion will be enhanced with decreasing density of the RSBW is still consistent with the literature on the scaling of $\varepsilon$ and/or $K_{\mathrm{z}}$. For example, Gargett and Holloway (1984) proposed that the scaling of $K_{\mathrm{Z}}$ is proportional to $N^{-1}$ or $K_{\mathrm{Z}}$ is proportional to $N^{-0.5}$ and furthermore, in the region near a topographic boundary, scalings which relate $K_{\mathrm{Z}}$ to the inverse of $N$ are

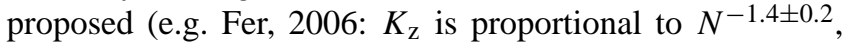
MacKinnon and Gregg, 2003: $K_{\mathrm{Z}}$ is proportional to $N^{-1}$ ).

Thirdly, in estimating the influence of the RSBW changes on AA-AABW, we assumed the box model of Eq. (10) in Sect. 3.3. As for RSBW volume transport $V_{\text {tr }}$, we used $7 \mathrm{~Sv}$ as a reference. This transport of $7 \mathrm{~Sv}$ corresponds to an average westward velocity of $17.5 \mathrm{~cm} \mathrm{~s}^{-1}$ at $150^{\circ} \mathrm{E}$, which is consistent with the velocity assumed in the model in Sect. 3.2. The validity of this value can be examined by considering the steady state heat balance in the AA-AABW. The heat flux induced by a RSBW volume transport of $7 \mathrm{~Sv}$ is estimated as $-0.71 \mathrm{~W} \mathrm{~m}^{-2}$ and this can be balanced by the heat flux induced by the vertical diffusion discussed in Sect. 2.2 $\left(0.67 \mathrm{~W} \mathrm{~m}^{-2}\right)$. Some limitations remain, such as the unknown influence of the supply of dense shelf water in the AGVL region, uncertainty of the effect of horizontal diffusion and uncertainty of the vertical diffusivity estimated by Polzin and Firing (1997). However, it is expected that our assumed volume transport would remain valid to the first order.

While the decrease in RSBW volume transport can be explained by a decrease in the dense shelf water export from the western Ross Sea, the weakening of the density stratification raises further questions. The weakening of vertical gradients of potential temperature and salinity from the $1970 \mathrm{~s}$ to $2000 \mathrm{~s}$ account for $32 \%$ and $68 \%$ of the decrease in $N^{2}$, respectively. This decrease in the vertical gradient of salinity can, in turn, be explained by the long-term freshening of the dense shelf water in the western Ross Sea (Jacobs and Giulivi, 2010). Hence, we suggest that freshening of the dense shelf water in the western Ross Sea also warmed the RSBW by enhancing the vertical diffusion of heat due to weakening of the density gradient.

\section{Summary and conclusions}

The WHP and repeated hydrographic data were used to examine changes in the AABW in the Australian-Antarctic Basin. Changes in average potential temperature and salinity below $\gamma^{n}=28.30 \mathrm{~kg} \mathrm{~m}^{-3}$ suggest a basin-wide warming 
$(1300 \pm 200 \mathrm{GW})$ and freshening $\left(24 \pm 3 \mathrm{Gt} \mathrm{year}^{-1}\right)$ of the AA-AABW. The RSBW also warmed, and at a faster rate than reported for its source waters. We infer that this warming is driven by a $21 \pm 23 \%$ reduction in the volume transport of the RSBW and enhanced vertical diffusion of heat as a result of a $30 \pm 7 \%$ decrease in density stratification. Freshening of the dense shelf water in the source region enhanced vertical mixing by reducing the salinity stratification between RSBW and the overlying ambient water. Hence, we propose that the freshening of the western Ross Sea source region directly freshened the RSBW downstream, and indirectly warmed the RSBW by enhancing vertical mixing. Our simple box model suggests that changes in the properties and volume transport of RSBW can explain $51 \pm 6 \%$ of the warming and $84 \pm 10 \%$ of the freshening of the AA-AABW.

Observations revealed the significant interannual variability of the AA-AABW. However, the interannual variability at I8S and I9S could not be taken into account because only two occupations of these lines were available. In addition, trends in the properties of RSBW used in the evaluation of the influence of RSBW changes on AA-AABW are specifically based on observations between the 1970s and 1990s because no data were available after 1996 near $150^{\circ} \mathrm{E}$.

Long-term changes in the dense shelf water formed in the AGVL region may also be important, but could not be estimated because of the lack of long-term observations in the area. Furthermore, it is pointed out from a modeling study that the 2010 calving of the Mertz Glacier tongue in this region could reduce the dense water export by up to $23 \%$ (Kusahara et al., 2011). Given the dynamic nature of the source regions on decadal to centenary time-scales, the influence on the AABW can be extensive. Hence, it is highly desirable to continue ongoing measurements programs in this area. As the steady state volume transport of the RSBW is a key parameter that determines its influence on AA-AABW, improved observations of its flow rates into the AustralianAntarctic Basin are critical.

\section{Appendix A}

Optimum Multiparameter (OMP) analysis is used to study the mixing process of the RSBW by defining water type of the HSSW and the LCDW. The OMP analysis is introduced by Tomczak (1981), and Tomczak and Large (1989) to estimate spatial distribution of water masses and their mixing process. As for potential temperature of the LCDW, we adopt $0^{\circ} \mathrm{C}$ for both periods of the 1970s and 2000s and corresponding salinity of 34.70 and 34.685 are given from $\theta$-S diagram. As for potential temperature and salinity of the HSSW, those of each period are adopted from regression lines shown in Fig. 3 of Jacobs and Giulivi (2010), which presented long term trend of both potential temperature and salinity of the
HSSW (as for the 1970s: $\theta=-1.89^{\circ} \mathrm{C}, S=34.83$, as for the 2000s: $\left.\theta=-1.87^{\circ} \mathrm{C}, S=34.74\right)$.

Acknowledgements. This work was supported by the fund from Grant-in-Aids for Scientific Research (20221001 and 21310002) of the Japanese Ministry of Education, Culture, Sports, Science and Technology. This work was also supported by the Australian Government's Cooperative Research Centre program through the Antarctic Climate and Ecosystem Cooperative Research Centre and by the Australian Climate Change Research Program. We thank the Topic editor and anonymous reviewer for their contribution to improvement of the manuscript.

Edited by: G. Williams

\section{References}

Aoki, S., Rintoul, S. R., Ushio, S., Watanabe, S., and Bindoff, N. L.: Freshening of the Adélie Land Bottom Water near $140^{\circ} \mathrm{E}$, Geophys. Res. Lett., 32, L23601, doi:10.1029/2005GL024246, 2005.

Bindoff, N. L. and McDougall, T. J.: Diagnosing Climate Change and Ocean Ventilation Using Hydrographic Data, J. Phys. Oceanogr., 24, 1037-1152, 1994.

Boyer, T. P., Antonov, J. I., Baranova, O. K., Garcia, H. E., Johnson, D. R., Locarnini, R. A., Mishonov, A. V., O’Brien, T. D., Seidov, D., Smolyar, I. V., and Zweng, M. M.: World Ocean Database 2009, edited by: Levitus, S., NOAA Atlas NESDIS 66, US Gov. Printing Office, Wash., D.C., 216 pp., DVDs, 2009.

Broecker, W. S.: Thermohaline circulation, the Achilles heel of our climate system: Will man-made $\mathrm{CO} 2$ upset the current balance?, Science, 278, 1582-1588, 1997.

Fer, I.: Scaling turbulent dissipation in an Arctic fjord, Deep-Sea Res. II, 53, 77-95, 2006.

Fukamachi, Y., Wakatsuchi, M., Taira, K., Kitagawa, S., Ushio, S., Takahashi, A., Oikawa, K., Furukawa, T., Yoritaka, H., Fukuchi, M., and Yamanouchi, T.: Seasonal variability of bottom water properties off Adélie Land, Antarctica, J. Geophys. Res., 105, 6531-6540, 2000.

Fukamachi, Y., Rintoul, S. R., Church, J. A., Aoki, S., Sokolov, S., Rosenberg, M. A., and Wakatsuchi, M.: Strong export of Antarctic Bottom Water east of the Kerguelen plateau, Nat. Geosci., 3, 327-331, doi:10.1038/ngeo842, 2010.

Gargett, A. E. and Holloway, G.: Dissipation and diffusion by internal wave breaking, J. Marine Res., 42, 15-27, 1984.

Gordon, A., Zambianchi, E., Orsi, A., Visbeck, M., Giulivi, C., Whitworth, T., and Spezie, G.: Energetic plumes over thewestern Ross Sea continental slope, Geophys. Res. Lett., 31, L21302, doi:10.1029/2004GL020785, 2004.

Gordon, A., Orsi, A., Muench, R., Huber, B., Zambianchi, E., and Visbeck, M.: Western Ross Sea continental slope gravity currents, Deep-Sea Res. II, 56, 796-817, 2009.

Gregg, M. C.: Scaling turbulent dissipation in the thermocline, J. Geophys. Res., 94, 9686-9698, 1989.

Jacobs, S. S.: Bottom water production and its links with the thermohaline circulation, Antarct. Sci., 16, 427-437, 2004. 
Jacobs, S. S.: Observations of change in the Southern Ocean, Philos. T. R. Soc. A., 364, 1657-1681, doi:10.1098/rsta.2006.1794, 2006.

Jacobs, S. S. and Giulivi, C. F.: Large Multidecadal Salinity Trends near the Pacific-Antarctic Continental Margin, J. Climate, 23, 4508-4524, 2010.

Jacobs, S. S., Giulivi, C. F., and Mele, P. A.: Freshening of the Ross Sea during the late 20th century, Science, 297, 386-389, 2002.

Johnson, G. C., Purkey, S. G., and Bullister, J. L.: Warming and Freshening in the Abyssal Southeastern Indian Ocean, J. Climate, 21, 5351-5363, 2008.

Kawano, T., Doi, T., Uchida, H., Kouketsu, S., Fukasawa, M., Kawai, Y., and Katsumata, K.: Heat Content Change in the Pacific Ocean between the 1990s and 2000s, Deep-Sea Res. II, 57, 1141-1151, 2009.

Kunze, E., Firing, E., Hummon, J. M., Chereskin, T. K., and Thurnherr, A. M.: Global Abyssal Mixing Inferred from Lowered ADCP Shear and CTD Strain Profiles, J. Phys. Oceanogr., 36, 1553-1576, 2006.

Kusahara, K., Hasumi, H., and Williams, G. D.: Impact of the Mertz Glacier Tongue calving on dense water formation and export, Nature Communications, 2, 159, doi:10.1038/ncomms1156, 2011.

Ledwell, J. R., Watson, A. J., and Law, C. S.: Mixing of a tracer in the pycnocline, J. Geophys. Res., 103, 21499-21529, 1998.

Levitus, S., Antonov, J., and Boyer, T.: Warming of the world ocean, 1955-2003, Geophys. Res. Lett., 32, L23601, doi:10.1029/2004GL021592, 2005.

MacKinnon, J. and Gregg, M.: Mixing on the late-summer New England shelf-Solibores, shear, and strati?cation., J. Phys. Oceanogr., 33, 1476-1492, 2003.

Masuda, S., Awaji, T., Sugiura, N., Mathews, J. P., Toyoda, T., Kawai, Y., Doi, T., Kouketsu, S., Igarashi, H., Katsumata, K., Uchida, H., Kawano, T., and Fukasawa, M.: Simulated Rapid Warming of Abyssal North Pacific Waters, Science, 329, 319322, 2010.

Muench, R., Padman, L., Gordon, A., and Orsi, A.: A dense water outflow from the Ross Sea, Antarctica: Mixing and the contribution of tides, J. Marine Syst., 77, 369-387, 2009.

Orsi, A. H. and Wiederwohl, C. L.: A recount of Ross Sea waters, Deep-Sea Res. II, 56, 778-795, 2009.

Orsi, A. H., Johnson, G. C., and Bullister, J. L.: Circulation, mixing, and production of Antarctic Bottom Water, Prog. Oceanogr., 43, 55-109, 1999.

Osborn, T. R.: Estimates of the Local Rate of Vertical Diffusion from Dissipation Measurements, J. Phys. Oceanogr., 10, 83-89, 1980.

Polzin, K. L. and Firing, E.: Estimates of diapycnal mixing using LADCP and CTD data from I8S, International WOCE Newsletter, 29, 39-42, 1997.
Purkey, S. G. and Johnson, G. C.: Warming of Global Abyssal and Deep Southern Ocean Waters between the 1990s and 2000s: Contribution to Global Heat and Sea Level Rise Budgets, J. Climate, 23, 6336-6351, 2010.

Purkey, S. G. and Johnson, G. C.: Global contraction of Antarctic Bottom Water between the 1980s and 2000s, J. Climate, in press, doi:10.1175/JCLI-D-11-00612.1, 2012.

Rintoul, S. R.: On the origin and influence of Adélie Land Bottom Water, Ocean, Ice and Atmosphere: Interactions at Antarctic Continental Margin, Antarct. Res. Ser., 75, 151-171, 1998.

Rintoul, S. R.: Rapid freshening of Antarctic Bottom Water formed in the Indian and Pacific Oceans, Geophys. Res. Lett., 34, L06606, doi:10.1029/2006GL028550, 2007.

Rivaro, P., Massolo, S., Bergamasco, A., Castagno, P., and Budillon, G.: Chemical evidence of the changes of the Antarctic Bottom Water ventilation in the western Ross Sea between 1997 and 2003, Deep-Sea Res. I, 57, 639-652, 2010.

Stein, C. and Stein, S.: A model for the global variation in oceanic depth and heat flow with lithospheric age, Nature, 359, 123-129, 1992.

Tamura, T., Ohshima, K. I., and Nihashi, S.: Mapping of sea ice production for Antarctic coastal polynyas, Geophys. Res. Lett. 35, L07606, doi:10.1029/2007GL032903, 2008.

Tomczak, M.: A multiparameter extension of the temperature/salinity diagram techniques for the analysis of non-isopycnal mixing, Prog. Oceanogr., 10, 147-171, 1981.

Tomczak, M. and Large, D. G. B.: Optimum multiparameter analysis of mixing in the thermocline of the eastern Indian Ocean, the temperature/salinity diagram techniques for the analysis of nonisopycnal mixing, J. Geophys. Res., 94, 16141-16149, 1989.

Whitworth, T.: Two modes of bottom water in the Australian-Antarctic Basin, Geophys. Res. Lett., 29, 1073, doi:10.1029/2001GL014282, 2002.

Whitworth, T. and Orsi, A. H.: Antarctic Bottom Water production and export by tides in the Ross Sea, Geophys. Res. Lett., 33, L12609, doi:10.1029/2006GL026357, 2006.

Williams, G. D., Bindoff, N. L., Marsland, S. J., and Rintoul, S. R.: Formation and export of dense shelf water from the Adélie Depression, East Antarctica, J. Geophys. Res., 113, C04039, doi:10.1029/2007JC004346, 2008.

Williams, G. D., Aoki, S., Jacobs, S. S., Rintoul, S. R., Tamura, T., and Bindoff, N. L.: Antarctic Bottom Water from the Adélie and George V Land coast, East Antarctica (140-149 ${ }^{\circ}$ E), J. Geophys. Res., 115, C04027, doi:10.1029/2009JC005812, 2010.

Zwally, H. J., Giovinetto, M. B., Li, J., Cornejo, H. G., Beckley, M. A., Brenner, A. C., Saba, J. L., and Yi, D. H.: Mass changes of the Greenland and Antarctic ice sheets and shelves and contribution to sea-level rise, 1992-2002, J. Glaciol., 51, 509-527, 2005. 